\title{
Crise do seguro saúde no chile: doença crônica socialmente transmissível
}

\section{Crisis of health insurance in chile: chronic socially transmissible disease}

\section{Crisis del aseguramiento de la salud en chile: enfermedad crónica socialmente transmisible}

Mario Parada-Lezcano

Fabian Moraga-Cortés ${ }^{2}$

\begin{abstract}
RESUMO: No Chile, desde o início da seguridade social em saúde sob responsabilidade estatal, em 1924, instalou-se uma crise de legitimidade da proteção social à saúde, porque nunca foi materializado o princípio da universalidade e os diferentes sistemas implantados excluíram a segmentos da população, gerando fragmentação e desigualdades. Serão desenvolvidas idéias sobre a persistente fragmentação classista do sistema de saúde enquanto forma de reprodução social, quase imune às concepções progressistas e à análise crítica de algumas propostas de mudanças estruturais. OBJETIVO: Analisar a evolução sócio-histórica da seguridade social em saúde no Chile, entre 1924 e 2018. METODOLOGIA: Ensaio. CONCLUSÕES: A luta por mudar o paradigma ideológico-hegemônico produz uma trajetória política em ziguezague. O caso chileno mostra poucos avanços e múltiplos retrocessos na garantia do direito à saúde. Observa-se una previdência social fragmentada com multiplicidade de sistemas de saúde; grande desigualdade nos resultados; contradição entre a herança estatista dos primeiros anos do século XX e a profunda neoliberalização da garantia propiciada pela ditadura. A fragmentação clássica dos sistemas de saúde e sua reprodução social, quase impermeável às concepções realmente próximas dos princípios da seguridade social, é o que chamamos de "doença socialmente transmissível".
\end{abstract}

Palavras Chave: Seguridade Social da Saúde. Seguro de Saúde. Direito à saúde.

1Profesor Titular de Salud Pública, Universidad de Valparaíso, Chile. Miembro de la ALASS. Email: mario.parada@, uv.cl

2Sociólogo y Magíster en Salud Colectiva.

ISSN 1982-8829 Tempus, actas de saúde colet, Brasília, 13(2), 177-203, jun, 2019. 
ABSTRAC: In Chile, since the beginning of the social security in health with State responsibility in 1924, a crisis of legitimacy of social protection in health has been installed, because the universality has never been fulfilled, the different systems implemented exclude some part of the population, generating fragmentation and inequality. We will develop ideas regarding the class fragmentation, as a form of social reproduction, almost impervious to more progressive conceptions and critical analysis of some proposals for structural changes. OBJECTIVE: To make a socio-historical analytical pathway of social security in Chilean health between 1924 and 2018 . METHODOLOGY: Assay. CONCLUSIONS: The struggle to change the hegemonic ideological paradigm produces a zigzagging political trajectory. The Chilean case shows few advances and multiple setbacks in the consolidation of the right to health and its assurance. We find a fragmented social security with a multiplicity of health systems; great inequality in the results, contradiction between the statist inheritance of the first decades of the 20th century and the acute neoliberalization of the assurance instalated in the dictatorship.

Classical fragmentation of health systems and their social reproduction, almost impervious to conceptions truly close to the principles of social security, is what we call "socially transmissible disease".

Key Words: Social Security in Health. Health Insurance. Right to health.

RESUMEN: En Chile, desde el inicio de la seguridad social en salud de responsabilidad del Estado en 1924, se ha instalado una crisis de legitimidad de la protección social en salud, ya que nunca se cumplió con el principio de universalidad, los diferentes sistemas implementados excluyen alguna parte de la población, generando fragmentación e inequidad. Desarrollaremos ideas respecto de la fragmentación clasista perpetuada, como forma de reproducción social, casi impermeable a concepciones más progresistas y análisis crítico de algunas propuestas de cambios estructurales. OBJETIVO: Realizar un recorrido analítico socio-histórico de la seguridad social en salud chilena entre 1924 y 2018. METODOLOGÍA: Ensayo. CONCLUSIONES: La lucha por cambiar el paradigma ideológico hegemónico, produce una trayectoria política zigzagueante. El caso chileno muestra pocos avances y múltiples retrocesos en la consolidación del derecho a la salud y su aseguramiento. Encontramos una seguridad social fragmentada con multiplicidad de sistemas de salud; gran inequidad en los resultados, contradicción entre la herencia estatista de los primeros años del siglo XX y la aguda neoliberalización del aseguramiento propiciados por la dictadura.

La fragmentación clasista de los sistemas sanitarios y su reproducción social, casi impermeable a concepciones verdaderamente cercanas a los principios de la seguridad social, es lo que denominamos como "enfermedad socialmente transmisible".

Palabras Clave: Seguridad Social en Salud. Aseguramiento en Salud. Derecho a la Salud.

\section{INTRODUCCIÓN}

Los sistemas de seguros son las formas de financiamiento de sistemas de salud que más se han Tempus, actas de saúde colet, Brasília, 13(2), 177-203, jun, 2019. ISSN 1982-8829 
desarrollado en las últimas décadas en el mundo. Recordamos que los seguros privados, aunque son sistemas de protección social, no forman parte de la Seguridad Social en Salud (SSS) la cual es de responsabilidad Estatal. La clasificación de Sistemas que utilizamos es la de tipos "ideales": a) Bismarkianos o de Seguridad Social (financiados por cotizaciones obligatorias, asociados al empleo formal); b) Bedgverianos o del Bienestar (financiados por impuestos generales, universales); Socialistas (comunistas, universales); Liberales (administrados por seguros privados con o sin fines de lucro). Si bien es cierto que el sistema creado por Bismarck contiene la lógica de "seguros"(pago de una especie de "prima" que "asegura" frente a ciertos "siniestros"), se sostiene en principios que defienden estos sistemas como sociales: universalidad, solidaridad, obligatoriedad, sustentabilidad, participación.

En Chile los especialistas hablan de aseguramiento en vez de sistemas de financiamiento; de protección social erróneamente como sinónimo de seguridad social. Por otra parte, usamos la siguiente conceptualización de las funciones de todo sistema de salud (ver figura 1), lo cual ayuda al análisis y clasificación de estos. Se advierte que, si bien los sistemas de salud contribuyen a la producción social de la salud, son apenas uno de los Determinantes Sociales de la Salud (DSS), y por tanto, no dan cuenta de la complejidad de la situación de salud de las comunidades.

\section{Figura 1: Modelo general de funciones de los sistemas de salud}

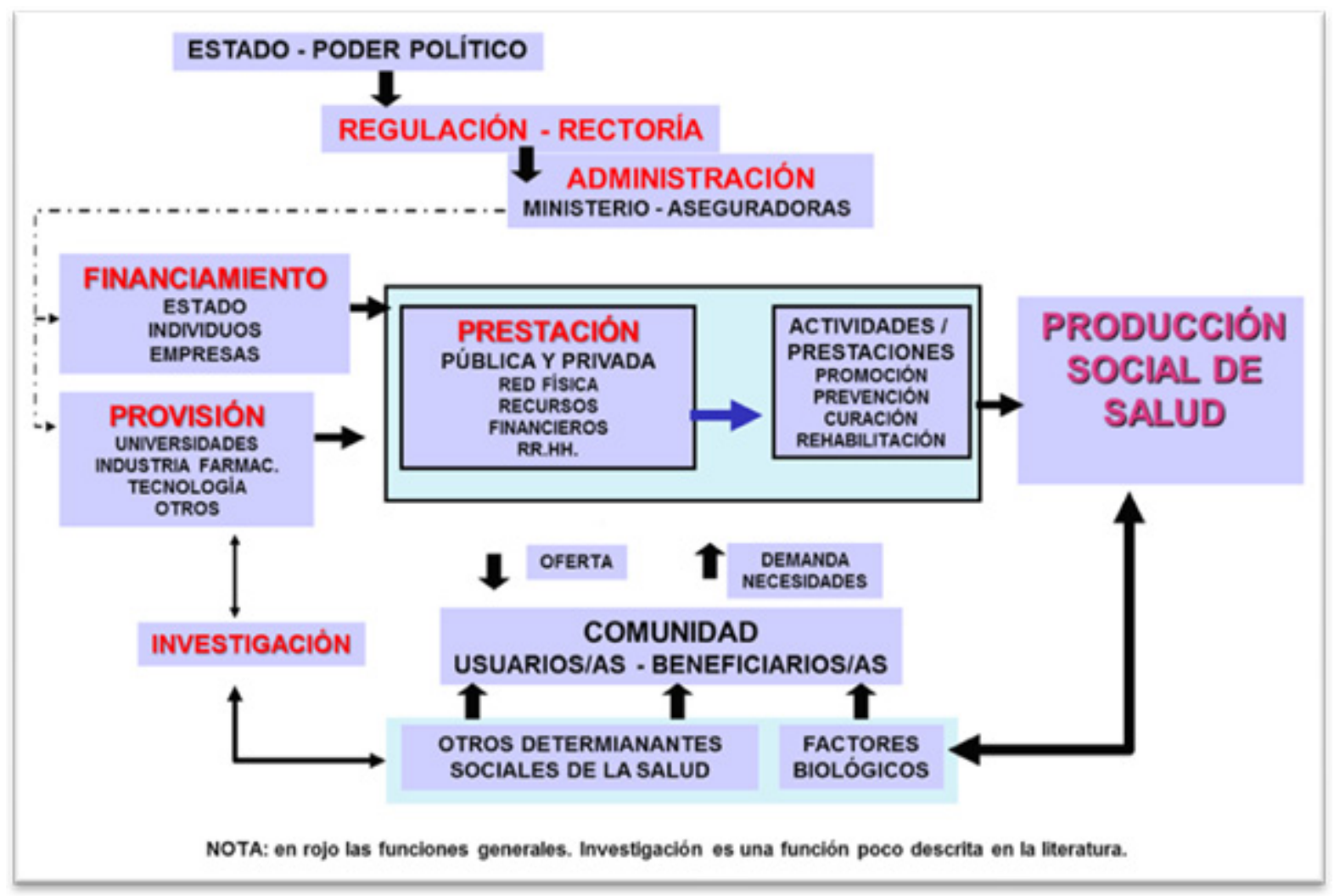

Fuente: Elaboración Propia

Desde el inicio de la SSS chilena, como responsabilidad del Estado (1924), se ha instalado ISSN 1982-8829 Tempus, actas de saúde colet, Brasília, 13(2), 177-203, jun, 2019. 
una crisis de legitimidad debida a que nunca se ha cumplido con el principio de universalidad. Los diferentes sistemas ensayados siempre han excluido a parte de la población, generando fuertes tensiones por la fragmentación e inequidad que produce $(1,2)$; se trata de una crisis, una "enfermedad crónica".

La hipótesis general apunta a que las transformaciones y proyectos de reforma a la SSS reprodujeron la fragmentación clasista en el sistema de salud, perpetuándola como forma de reproducción social, casi impermeable a concepciones contrahegemónicas. Adicionalmente, como hipótesis secundaria, se plantea que ello fue resultado de una combinación particular entre el posicionamiento de sujetos claves, el contexto histórico-social de cada época, el espacio de discusión utilizado, y el contenido final de las diferentes políticas implementadas. La correlación entre estas cuatro dimensiones favoreció, en cada uno de los momentos analizados, la perpetuación clasista de la SSS.

Utilizamos el marco de la medicina social, síntesis teórica que entiende salud-enfermedadatención como fenómeno social de primera importancia, que se construye socialmente y que construye sociedad; entendiendo el derecho a la salud (DS) como una construcción social compleja, que requiere ser estudiada de manera interdisciplinaria, utilizando herramientas teóricas y metodológicas que den cuenta de dicha complejidad $(3,4,5,6)$. El caso chileno ha sido prototípico en América Latina desde los 80, y muestra rasgos comunes con el resto de países, al haber sido la nación en donde el neoliberalismo se introdujo de forma mástemprana $(7,8,2)$.

\section{SISTEMAS DE ASEGURAMIENTO DE LA SALUD EN CHILE 1924 - 1990}

Hasta inicios del siglo XX la atención médica en Chile estuvo a cargo de las instituciones de la beneficencia, la iglesia católica y las Sociedades de Socorros Mutuos (ver tabla 1).

Tabla 1: Reseña cronológica de la evolución histórica de la salud en Chile 1451 - 1920

\begin{tabular}{|c|l|}
\hline Año & \multicolumn{1}{|c|}{ Evento } \\
\hline 1451 & El Cabildo se encarga de la “policía sanitaria” a la usanza del reino de España. \\
\hline 1552 & $\begin{array}{l}\text { Fundación del primer hospital de } 50 \text { camas para la atención de los “menesterosos”, posteriormente } \\
\text { entregado a la Congregación de los Hermanos de San Juan de Dios. }\end{array}$ \\
\hline 1808 & Creación de la Junta Central de Vacunaciones. \\
\hline 1832 & Creación de la Junta de directores de hospital y Casa de Expósitos. \\
\hline 1842 & Creación de la Facultad de Medicina de la Universidad de Chile. \\
\hline 1844 & Creación de las Juntas de Beneficencia y Salud Pública. \\
\hline 1886 & Promulgación de la ley de Policía Sanitaria y del Reglamento Orgánico de la Junta de Beneficencia. \\
\hline 1887 & $\begin{array}{l}\text { Creación de la Junta General de Salubridad, con el propósito de asesorar al gobierno en materias de } \\
\text { salubridad. }\end{array}$ \\
\hline 1891 & $\begin{array}{l}\text { Promulgación de la ley de organización y atribuciones de las Municipalidades, en donde se hace a estas } \\
\text { responsables de la higiene pública. }\end{array}$ \\
\hline 1892 & $\begin{array}{l}\text { Promulgación de la ley de Higiene Pública con la creación del Consejo de Higiene Pública, que } \\
\text { reemplaza a la Junta General de Salubridad. }\end{array}$ \\
\hline 1900 & Creación del Patronato Nacional de la Infancia y de las “Gota de leche”. \\
\hline
\end{tabular}

Tempus, actas de saúde colet, Brasília, 13(2), 177-203, jun, 2019. ISSN 1982-8829 


\begin{tabular}{|l|l|}
\hline 1917 & $\begin{array}{l}\text { Creación del Consejo Superior de Beneficencia, que consolida el proceso de dar unicidad técnica a } \\
\text { todos los hospitales del país. }\end{array}$ \\
\hline 1918 & $\begin{array}{l}\text { Primer Código Sanitario, con la creación de la Dirección de Sanidad y organismos sanitarios en cada } \\
\text { zona de salubridad. }\end{array}$ \\
\hline
\end{tabular}

Fuente: María Eliana Labra (1)

El inicio de la SSS es en 1924 con la creación de la Caja del Seguro Social Obrero Obligatorio (SSOO), primero de su tipo en América Latina, con asistencia médica gratuita con aportes de trabajadores, empleadores y el fisco. De facto este Seguro fue una respuesta de la élite contra las sociedades de socorros mutuos de autogestión obrera-comunitaria. En este contexto, la Salud Pública impulsóla realización de campañas sanitarias de higiene pública y el registro y uso de estadísticas en salud. La exclusión de funcionarios públicos y empleados particulares marca el "error congénito" de la enfermedad crónica de la SSS. La universalidad faltante aparece como el gran desafío del Frente Popular en 1938, con el Ministro de Salud socialista Dr. Salvador Allende G., quien formula el Proyecto de creación de "una gran Caja de previsión nacional única", de un "Consejo Nacional de Salubridad", un "Servicio Nacional de Salubridad" el cual "traerá acompañada la escala médica única" $(1941)(1,9,10)$.

Tabla 2: Paradigmas en juego en Chile en la década de 1940-50

\begin{tabular}{|c|c|c|}
\hline Liberal-conservador & De Seguridad Social & Socialista \\
\hline $\begin{array}{l}\text { Transformar el Seguro obligatorio } \\
\text { en un fondo individual de } \\
\text { capitalización del asalario, también } \\
\text { de tipo obligatorio } \\
\text { La contribución previsional, por el } \\
\text { hecho de exigir contraprestación, } \\
\text { pertenece a cada individuo, que } \\
\text { tiene pleno derecho a depositarla } \\
\text { cada mes en una cuenta personal; } \\
\text { "Al convertirse todo el mundo } \\
\text { en un pequeño propietario, } \\
\text { simplemente se suprimía para } \\
\text { siempre la diferencia de clases } \\
\text { sociales" }\end{array}$ & $\begin{array}{l}\text { Tomado de la OIT, positivista y } \\
\text { racionalista,proveer a los más } \\
\text { modestos ciudadanos de los } \\
\text { elementos indispensables para suplir } \\
\text { las necesidades de la vida (médicos, } \\
\text { farmacias, subsidios, etc.) } \\
\text { "en las mismas condiciones en que } \\
\text { pueden hacerlos aquellos que ocupan } \\
\text { una situación más holgada en la vida" } \\
\text { implicaban extinguir la Beneficencia, } \\
\text { así como todo tipo de asistencia } \\
\text { mínima estatal, porque "el bienestar } \\
\text { público es objeto de previsión social } \\
\text { y derechos de los ciudadanos". }\end{array}$ & $\begin{array}{l}\text { Estatización de todas las } \\
\text { funciones, junto con la } \\
\text { conversión de los médicos en } \\
\text { servidores públicos. } \\
\text { Integralidad de los problemas } \\
\text { médicos asistenciales tanto } \\
\text { en el sentido de etapas de } \\
\text { vida humana, como en los } \\
\text { aspectos físico, social, moral e } \\
\text { intelectual. } \\
\text { Comando técnico único } \\
\text { y autoridad legal para } \\
\text { hacer cumplir las acciones } \\
\text { planificadas. }\end{array}$ \\
\hline
\end{tabular}

Fuente: María Elinana Labra (1)

La propuesta de Allende, adelantada a su tiempo, "durmió" 10 años en el Congreso Nacional. En los 50 se retoma el debate y junto con desechar esta propuesta de Allende se configura, la creación del Servicio Nacional de Salud (SNS) (1952). SNS es la unificación, en una sola estructura de cobertura nacional y comando centralizado (autónomo respecto del MINSAL), de todos los servicios de atención médica, hospitalaria y de salud pública del país, para los obreros e indigentes. Se mantuvo el financiamiento bismarkiano tripartito (trabajadores, empleadores y Estado) y se deja nuevamente excluidos a los empleados públicos agrupados en el Servicio Médico Nacional (SERMENA), creado en 1942.El SNS se diferenció claramente del NHS inglés, al cual imitaba, ya que el europeo era bedveridgiano e universal. La medicina privada era irrelevante, lo cual mantenía

ISSN 1982-8829 Tempus, actas de saúde colet, Brasília, 13(2), 177-203, jun, 2019. 
descontentos a los médicos liberales, por lo que en 1968 se implementó una solución "sui generis" para dar fuerza al desarrollo privado a través de la Ley de Medicina Curativa, apoyada también por los sectores medios (empleados agrupados en la Asociación nacional de Empleados Fiscales ANEF y la Central de Empleados Particulares de Chile - CEPCH): atención particular de empleados utilizando infraestructura del SNS, pagando un "cheque bono" (sistema de libre elección - MLE), con un financiamiento contributivo a través de las "cajas" ocupacionales; quedando el trabajo médico asalariado en el SNS y el "bonificado" liberal para los empleados.

Paralelamente, se instaura el primer sistema de aseguramiento propiamente dicho (prima variable de acuerdo al riesgo), Seguro de Salud Laboral (SSL) para trabajadores asalariados (daño por accidentes laborales y enfermedades profesionales): financiamiento entregado por los patrones y administración por empresas privadas sin fines de lucro conocidas como "mutuales".El gobierno de la Unidad Popular (1970-73) del Presidente Allende, retomó los principios médico sociales y la idea del Sistema Nacional Único de Salud (SUS). Si bien esta propuesta fue inicialmente compartida por todo el espectro político, nunca se concretó en un proyecto de ley. Allende abolió el MLE, lo que sumado a la oposición médica a la idea del SUS, gatilló que el poderoso Colegio Médico llamara a huelga general, exigiera la renuncia del Presidente y llamara públicamente a la intervención militar. $(1,9,2)$.

Tabla 3: Reseña cronológica de la evolución histórica de la saluden Chile 1924 - 1973

\begin{tabular}{|c|c|}
\hline Año & Evento \\
\hline 1924 & $\begin{array}{l}\text { SEGURO SOCIAL OBRERO OBLIGATORIO (SSOO) } \\
\text { Asistencia médica gratuita, en ambulatorios propios y en los hospitales de la Beneficencia Pública } \\
\text { (también atiende pobres e indigentes). Funcionarios públicos y empleados particulares: excluidos }\end{array}$ \\
\hline 1925 & $\begin{array}{l}\text { Promulgación de la nueva Constitución Política } \\
\text { Se crea la junta central de Beneficencia. }\end{array}$ \\
\hline 1938 & $\begin{array}{l}\text { Ley de Medicina Preventiva } \mathbf{N}^{\mathbf{0}} \mathbf{6 . 1 7 4} \text {, Se deseaba que el Estado por intermedio de la "medicina } \\
\text { dirigida" actuara sobre "la máquina", o sea los trabajadores. Tres medidas principales: examen } \\
\text { sistemático, periódico y obligatorio de la salud; reposo para tratamiento de las enfermedades } \\
\text { incipientes; remuneración de ese reposo. } \\
\text { Ley } \mathbf{N}^{\circ} \mathbf{6 . 2 3 6} \text { de 1938, conocida como de la madre-niño, estableció el examen médico preventivo } \\
\text { de la mujer embarazada y el control periódico del niño hasta los dos años, entregando los } \\
\text { medicamentos y los alimentos necesarios. }\end{array}$ \\
\hline 1942 & $\begin{array}{l}\text { Creación de la Dirección General de Protección a la Infancia y Adolescencia - PROTINFA } \\
\text { Creación del Servicio Médico nacional de Empleados - SERMENA, fusión de los } \\
\text { departamentos de salud de las cajas de empleados Públicos y particulares. }\end{array}$ \\
\hline 1943 & Fundación de la Escuela de Salubridad \\
\hline 1945 & Creación de la OMS y la CEPAL \\
\hline 1946 & Creación del Instituto Bacteriológico \\
\hline 1948 & Creación del Colegio Médico \\
\hline 1951 & $\begin{array}{l}\text { Dictación de la Ley } 10.223 \text { del Médico Funcionario, conocida popularmente como del "médico } \\
\text { millonario" }\end{array}$ \\
\hline
\end{tabular}

Tempus, actas de saúde colet, Brasília, 13(2), 177-203, jun, 2019. ISSN 1982-8829 


\begin{tabular}{|c|l|}
\hline \multirow{1}{*}{1952} & $\begin{array}{l}\text { SERVICIO NACIONAL DE SALUD - SNS } \\
\text { Ley 10.383, unifica todos los servicios de atención médica, hospitalaria y de salud pública de país, } \\
\text { crea el Consejo Nacional de Salud: lugar formal para la toma de decisiones } \\
\text { Categorías de empleados: sin derecho legal a la medicina estatal } \\
\text { Por ley, el SNS debería proveer cuidados médicos y hospitalarios solamente a los obreros y a los } \\
\text { indigentes. En la práctica, cubría el 75\% de la población (excepto fuerzas armadas y policías) }\end{array}$ \\
\hline 1958 & $\begin{array}{l}\text { Creación de la Mutualidades de Seguridad para la protección de riesgos laborales de trabajadores } \\
\text { privados }\end{array}$ \\
\hline \multirow{1}{*}{1968} & $\begin{array}{l}\text { LEY DE MEDICINA CURATIVA } \\
\text { Extiende la cobertura del SNS a los empleados, pero mediante reglas propias de la medicina } \\
\text { con el Colegio Médico.El SNS pasa a atender el 90\% de la población (fuerzas armadas y policías } \\
\text { mantienen sistemas propios) } \\
\text { LEY 16.744. de Seguridad Laboral } \\
\text { Protección freta a accidentes Laborales y enfermedades Profesionales, facultando a las Mutuales } \\
\text { para su administración, con cotización obligatoria de los empleadores particulares, se excluye al } \\
\text { Estado. }\end{array}$ \\
$\begin{array}{l}\text { Allende retomó los fundamentos de la realidad médico social chilena que venía defendiendo desde } \\
\text { los años treinta. Proyecto del Presidente Salvador Allende de crear el Sistema Unificado de Salud } \\
- \text { SUS, no es presentado } \\
\text { Ley de democratización del SNS y de la caja de empleados particulares (dirección elegida por } \\
\text { imponentes) }\end{array}$ \\
\hline $1971-1973$
\end{tabular}

Fuente: Basado en María Eliana Labra (1)

Con el golpe militar se inicia la contrarrevolución de signo neoliberal, con profundas reformas $(1,2)$.

Tabla 4: Transformaciones neoliberales en la dictadura cívico militaren Chile 1973 - 1990

\begin{tabular}{|c|l|}
\hline Año & \multicolumn{1}{c|}{ Transformación } \\
\hline 1979 & $\begin{array}{l}\text { DL No } 2.763 \text { Fusionó SNS y SERMENA, creación de: Fondo Nacional de Salud - FONASA y el Sistema } \\
\text { Nacional de Servicios de Salud (SNSS - 26 Servicios regionales). El SERMENA pasa a ser el FONASA. Se } \\
\text { crea la Central Nacional de Abastecimiento (CENABAST) y el Instituto de Salud Pública (ISP) ex Instituto } \\
\text { bacteriológico. }\end{array}$ \\
\hline 1980 & $\begin{array}{l}\text { Nueva Constitución Política señala que “el Estado protege el libre e igualitario acceso a las acciones de } \\
\text { promoción, protección y recuperación de la salud y de rehabilitación del individuo (...) Es deber preferente } \\
\text { del Estado garantizar la ejecución de las acciones de salud, sea que se presten a través de instituciones } \\
\text { públicas o privadas, en la forma y condiciones que determine la ley, la que podrá establecer cotizaciones } \\
\text { obligatorias. Cada persona tendrá el derecho a elegir el sistema de salud al que desee acogerse, sea éste } \\
\text { estatal o privado" (11). }\end{array}$ \\
\hline 1980 & $\begin{array}{l}\text { Aumento de cotización obligatoria para salud del } 4 \text { al 7\% del sueldo. Se elimina sistema tripartito, quedando } \\
\text { solo el aporte del trabajador y del Estado. }\end{array}$ \\
\hline 1981 & $\begin{array}{l}\text { DFL 13.063 inició el proceso de municipalización de la Atención Primaria de Salud (APS), tradicionalmente } \\
\text { parte constitutiva del SNS. }\end{array}$ \\
\hline $\begin{array}{l}\text { DFL No 3. Privatización de la SSS a través de la creación de las Instituciones de Salud Previsional en Salud } \\
\text { (ISAPRE), empresas aseguradoras privadas con fines de lucro, que administran la cotización obligatoria } \\
\text { para salud (7\% del sueldo) para la población de más altos ingresos económicos }\end{array}$ \\
\hline $\begin{array}{l}\text { Se estimó innecesario mantener la “odiosa" distinción entre obreros y empleados que existía en el sistema } \\
\text { anterior, por lo que se promulgó una Ley que unificó el régimen de prestaciones del sistema público. Ya } \\
\text { no era necesario hacer distinciones de clase a través del lenguaje, ya que se institucionalizaron a través } \\
\text { de la creación de las ISAPRE, la cual realiza la discriminación según el nivel de ingresos económicos. Se } \\
\text { establecen copagos de acuerdo a nivel de ingreso económico dentro de FONASA (A, B, C y D) }\end{array}$ \\
\hline
\end{tabular}

ISSN 1982-8829 Tempus, actas de saúde colet, Brasília, 13(2), 177-203, jun, 2019. 


\begin{tabular}{|c|l|}
\hline 1986 & $\begin{array}{l}\text { Ley } 18.566 \text { crea sistema de subsidio cruzado estatal dado que permite el financiamiento de planes colectivos } \\
\text { en ISAPRE con un } 2 \% \text { de cotización adicional pagado por el empleador pero descontado de Impuestos. }\end{array}$ \\
\hline 1990 & Creación de la Superintendencia de ISAPRE, ente fiscalizador del sistema de aseguramiento privado. \\
\hline
\end{tabular}

Fuente: Basado en Labra (8)

Las ISAPRE, son la "joya de la corona” luego de la destrucción del SNS, la municipalización de la APS y sobre todo la instalación del Rol Subsidiario del Estado en la Constitución de 1980. Estas son empresas de seguros de salud privados con fines de lucro, que cobran como prima base, independiente del riesgo de la persona, el 7\% del sueldo; situación que las hace totalmente excepcionales en la experiencia comparada, ya que utilizan la cotización obligatoria como prima de entrada, independiente del riesgo real de la persona a asegurar, generando el incentivo primigenio de descremar el mercado privilegiando los clientes hombres, sanos y jóvenes. Si la falta de universalidad o la exclusión es el "error congénito" de la SSS, las ISAPRE se constituyen en "engendro" dentro de ella nacido del neoliberalismo, apuntada como una comparación insostenible. Consecuentemente, la implementación de las ISAPRE representa la política más expresiva de la persistente exclusión de la SSS.

Sobre aquello,cobra según riesgo de salud individual, primas que pueden variar hasta cuatro veces de acuerdo a la edad y el sexo, y variando además según la cantidad de personas afiliadas a cada plan. Si el 7\% no alcanza a cubrir un plan deseado, se debe agregar un monto adicional (prepago), que en promedio alcanza otro 3\% de la renta imponible. Se establecieron subsidios estatales indirectos a las ISAPRE para aumentar la cobertura. Por su parte, el SNSS sufrió una fuerte reducción de aportes de parte del Estado, de 2\% a 0,8 \% del PIB (12). Las ISAPRE discriminan por sexo, edad, estado de salud (preexistencias) y situación económica.

Las repercusiones de la privatización de la SSS se expresan en el aumento de la complejidad en la administración de los sistemas, las grandes dificultades y esfuerzos para regular un sistema basado en el lucro; aumento de costos y precios muy poco regulados; y la inequidad consiguiente entre sistemas (13). De facto generaron una crisis financiera del sector, ya que en los años 90 administraban $45 \%$ de los recursos mientras aseguraban solo al $27 \%$ de la población nacional (14). En 2000, las ISAPRE recibían 69\% de los recursos de las cotizaciones obligatorias, mientras que FONASA recibía el 31\% dos recursos, para atender el 64\% de la población (15).

\section{NEODEMOCRACIA Y SALUD - ENFERMEDAD - ATENCIÓN 1990 - 2010}

El recorrido socio histórico del Chile de los 90 muestra una sociedad en transición, desde muchos puntos de vista, pero sobre todo desde el punto de vista político. La inconclusa transición política generó una situación híbrida, la neodemocracia ${ }^{3}$. Se consolida un Estado liberal subsidiario, en un una sociedad autoritaria reacia al cambio y a la reflexión seria acerca de su futuro. Los valores de

3 Término acuñado por María Eliana Labra (1998) dada la particularidad del caso chileno, que en algunos ámbitos (constitucional por ejemplo) aún no culmina una transición clásica a la democracia sustantiva.

Tempus, actas de saúde colet, Brasília, 13(2), 177-203, jun, 2019. ISSN 1982-8829 
igualdad, solidaridad y justicia que habían sido promovidos en los 60 - 70, fueron reemplazados por el éxito individual, consumo masivo y un tipo de bienestar privatizado.

Cabe destacar que Bohm et al. (16) señalaron que 4 de los 34 países de la OCDE (Chile, Grecia, México y Turquía) fueron "inclasificables" debido a la falta de datos o la alta fragmentación que presentan.

En la Tabla siguiente mostramos la Fragmentación de sistemas de salud, con sus principales características.

Tabla 5: Sistemas de Aseguramiento en Salud en Chile. 2018

\begin{tabular}{|c|c|c|c|c|}
\hline Sistema & $\begin{array}{c}\text { Administración / } \\
\text { Tipo Principal }\end{array}$ & $\begin{array}{c}\text { Fuentes de } \\
\text { Financiamiento }\end{array}$ & Prestadores & $\begin{array}{c}\text { Características } \\
\text { Generales }\end{array}$ \\
\hline $\begin{array}{l}\text { SNSS - } \\
\text { FONASA }\end{array}$ & $\begin{array}{l}\text { Estatal } \\
\text { Bismarkiano }\end{array}$ & $\begin{array}{l}\text { Individuos: } \\
\text { - Cotizaciones } \\
\quad \text { obligatorias } \\
\text { - Copagos } \\
\text { - Otros gastos de } \\
\quad \text { bolsillo } \\
\text { Estado: } \\
\text { Subsidio a "indigentes" y } \\
\text { Bienes Públicos de toda } \\
\text { la población (campañas } \\
\text { sanitarias, etc.) } \\
\end{array}$ & $\begin{array}{l}\text { Estado } \\
\text { (Modalidad } \\
\text { de Atención } \\
\text { Institucional - } \\
\text { MAI) } \\
\text { Privados con } \\
\text { fines de lucro } \\
\text { (Modalidad de } \\
\text { Libre Elección } \\
\text { MLE y compra de } \\
\text { servicios) } \\
\end{array}$ & $\begin{array}{l}\text { Solidario } \\
\text { Cobertura } 80 \% \\
\text { población } \\
\text { Sin discriminación } \\
\text { Fiscalizado por } \\
\text { Superintendencia } \\
\text { de Salud (SIS) del } \\
\text { MINSAL }\end{array}$ \\
\hline ISAPRE & $\begin{array}{l}\text { Privada con fines } \\
\text { de lucro. Abiertas } \\
\text { y cerradas } \\
\text { Liberal }\end{array}$ & $\begin{array}{l}\text { Individuos } \\
\text { - } \text { Cotizaciones } \\
\text { obligatorias } \\
\text { - Prepagos } \\
\text { - } \text { Copagos } \\
\text { - Otros gastos de } \\
\quad \text { bolsillo }\end{array}$ & $\begin{array}{l}\text { Privados con fines } \\
\text { de lucro }\end{array}$ & $\begin{array}{l}\text { No solidario } \\
\text { Cobertura } 17 \% \\
\text { Población } \\
\text { Discrimina por } \\
\text { ingresos, estado de } \\
\text { salud, sexo y edad. } \\
\text { Fiscalizado por } \\
\text { Superintendencia } \\
\text { de Salud (SIS) del } \\
\text { MINSAL } \\
\end{array}$ \\
\hline $\begin{array}{l}\text { Fuerzas } \\
\text { Armadas y de } \\
\text { orden (FFAA) }\end{array}$ & $\begin{array}{l}\text { Estatal } \\
\text { Bismarkiano }\end{array}$ & $\begin{array}{l}\text { Individuos: } \\
\text { - Cotizaciones } \\
\text { obligatorias }(5,5 \%) \\
\text { - } \text { Copagos } \\
\text { - Otros gastos de } \\
\text { bolsillo } \\
\text { Estado como empleador: } \\
\text { - } 1,5 \% \text { de la cotización } \\
\text { obligatoria } \\
\text { - } 1 \% \text { para fondo de } \\
\text { medicina preventiva }\end{array}$ & $\begin{array}{l}\text { Estado (red } \\
\text { propia) }\end{array}$ & $\begin{array}{l}\text { Solidario } \\
\text { Cobertura 3\% } \\
\text { Sin fiscalización del } \\
\text { MINSAL, solo del } \\
\text { Ministerio de Defensa }\end{array}$ \\
\hline
\end{tabular}




\begin{tabular}{|c|c|c|c|c|}
\hline \multirow{3}{*}{$\begin{array}{l}\text { Seguro de } \\
\text { Accidentes } \\
\text { Laborales y } \\
\text { Enfermedades } \\
\text { Profesionales }\end{array}$} & $\begin{array}{l}\text { Privada Sin } \\
\text { fines de lucro: } \\
\text { Mutuales } \\
\text { Bismarkiano }\end{array}$ & $\begin{array}{l}\text { Empleadores } \\
\text { Individuos } \\
\text { - Otros gastos de } \\
\text { bolsillo }\end{array}$ & $\begin{array}{l}\text { Privados Sin fines } \\
\text { de lucro (red } \\
\text { propia) }\end{array}$ & $\begin{array}{l}\text { Solidario dentro de } \\
\text { cada mutual. } \\
\text { No existen mecanismos } \\
\text { de redistribución inter- } \\
\text { mutual, ni con el ISL. } \\
\text { Cobertura } 70 \% \\
\text { trabajadores } \\
\text { asalariados. } \\
\text { Fiscalizadas por } \\
\text { Superintendencia } \\
\text { de Seguridad Social } \\
\text { (SUSESO) del } \\
\text { Ministerio del Trabajo } \\
\text { y previsión social }\end{array}$ \\
\hline & $\begin{array}{l}\text { Estatal: Instituto } \\
\text { de Seguridad } \\
\text { Laboral ISL } \\
\text { Bismarkiano }\end{array}$ & 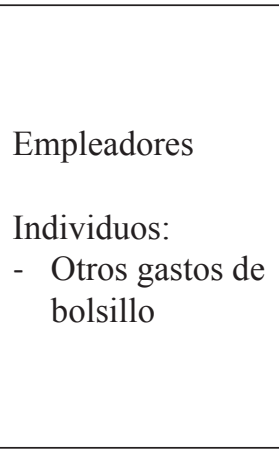 & $\begin{array}{l}\text { Privados con } \\
\text { fines de lucro y } \\
\text { Públicos }\end{array}$ & $\begin{array}{l}\text { Solidario } \\
\text { ISL tiene algunos } \\
\text { programas a los } \\
\text { desprotegidos esto lo } \\
\text { realiza en conjunto con } \\
\text { MINSAL. Fiscalizadas } \\
\text { por Superintendencia } \\
\text { de Seguridad Social } \\
\text { (SUSESO) del } \\
\text { Ministerio del Trabajo } \\
\text { y previsión social }\end{array}$ \\
\hline & $\begin{array}{l}\text { Estatal: } \\
\text { Administración } \\
\text { delegada a } \\
\text { grandes empresas } \\
\text { estatales (ej. } \\
\text { CODELCO) } \\
\text { Bismarkiano }\end{array}$ & 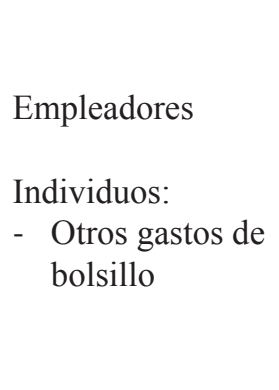 & $\begin{array}{l}\text { Privados con } \\
\text { fines de lucro y } \\
\text { Públicos }\end{array}$ & $\begin{array}{l}\text { Solidario dentro de } \\
\text { cada administración } \\
\text { delegada. } \\
\text { Fiscalizadas por } \\
\text { Superintendencia } \\
\text { de Seguridad Social } \\
\text { (SUSESO) del } \\
\text { Ministerio del Trabajo } \\
\text { y previsión social }\end{array}$ \\
\hline Teletón & $\begin{array}{l}\text { Privada sin fines } \\
\text { de lucro } \\
\text { Liberal }\end{array}$ & $\begin{array}{l}\text { Individuos: } \\
\text { a través de caridad } \\
\text { (colecta nacional } \\
\text { televisada) }\end{array}$ & $\begin{array}{l}\text { Privados sin fines } \\
\text { de lucro (red } \\
\text { propia) }\end{array}$ & $\begin{array}{l}\text { Solidario } \\
\text { Da cobertura al 100\% } \\
\text { de niños/as con } \\
\text { discapacidades físicas. } \\
\text { Sin discriminación. } \\
\text { Fiscalizado por } \\
\text { Superintendencia } \\
\text { de Salud (SIS) del } \\
\text { MINSAL }\end{array}$ \\
\hline
\end{tabular}

Fuente: Mario Parada (17).

El Sistema sanitario de FFAA, funciona a través de un esquema de fondos, uno de Medicina Curativa financiado por la imposición del 5,5\% de las remuneraciones y por el aporte del 1,5\% sobre las remuneraciones, de cargo del empleador (Estado); otro de Medicina Preventiva financiado por la imposición del 1\% sobre las remuneraciones a cargo del respectivo empleador (Estado) (18). Esta situación marca una inequidad del sistema de financiamiento de la salud en Chile, la cual no ha sido considerada en ninguna discusión y/o propuesta al respecto, manteniendo la cultura de "silencio o secreto" respecto de los asuntos castrenses.

Los datos sobre financiamiento agregado de la salud en Chile muestran que el gasto público 
y privado representan, respectivamente, 3,8\% y 4,0\% del PIB; además, la principal fuente de los recursos es el gasto de bolsillo, próximo al 40\% del gasto total, siendo fuertemente determinado por el gasto en medicamentos $(20,21)$. El gasto de bolsillo es altamente inequitativo, porque cada persona accede a los servicios según su capacidad individual de pago, siendo fuertemente empobrecedor cuando supera determinado nivel del presupuesto familiar.

Cabe destacar que desde 2008 las cuentas públicas o gubernamentales incluyen el gasto de las cotizaciones obligatorias del sistema ISAPRE como Gasto Público, y no como Privado tal como era hasta antes de esa fecha y como debería ser considerado correctamente, ya que esos fondos son administrados por empresas con fines de lucro, sin cumplir ningún otro principio de la Seguridad social más que el de la obligatoriedad. Las razones para dicho cambio "administrativo" se desconocen.

Chile mantiene un bajo gasto per cápita comparado con países europeos con una altísima proporción de gasto privado(22). Además, de no mediar cambios estructurales, según un reciente estudio de Cid et al.(23), Chile alcanzaría la recomendación de la OMS de un gasto Público equivalente al 6\% del PIB recién en el año 2035. Si dicha proyección es correcta, implicaría que Chile alcanzaría ese mismo año un gasto total cercano al 12\% del PIB (50\% privado). Agrega el estudio que "los países de América Latina y el Caribe que la han logrado (meta de gasto público de $6 \%$ del PIB) son aquellos que mantienen sistemas de salud únicos, basados en acceso y cobertura universales" (23).

El sector público (FONASA-SNSS), cuenta con un solo plan (a través de 2 modalidades de atención, la institucional - MAI y la libre elección - MLE) financiado con el 7\%, cualquiera sea el tamaño familiar u otros factores de riesgo del afiliado o su familia y con copago de acuerdo a la modalidad de atención ( $20 \%$ como máximo en MAI). Existe aporte de fondos públicos provenientes de impuestos generales que representan de un 58,4\% del presupuesto del FONASA.

Las ISAPRE abiertas corresponden a un "cuasi mercado" de aseguramiento de salud con oferentes que persiguen lucro; las ISAPRE cerradas, se pueden considerar como parte de la Seguridad Social de trabajadores de empresas públicas "privilegiadas" (CODELCO, Ferrocarriles EFE, etc.). Se diferencian, además, por no perseguir lucro como finalidad última de la organización (24).

En 1999, se da un hecho significativo de la trayectoria del aseguramiento privado ya que una ley estableció que los "excedentes" de las cotizaciones obligatorias son de propiedad del afiliado y deben ser reembolsados obligatoriamente. La "legalización" del concepto de propiedad individual de las cotizaciones de Seguridad Social fue un revés muy potente que se les dio a las pretensiones progresistas en aquellos instantes y para el futuro.

En el año 2000 las ISAPRE acordaron por la vía de la autorregulación proponer a la Superintendencia la creación de un seguro catastrófico, que sería entregado a toda la cartera de 
beneficiarios para enfrentar los eventos que generaran una catástrofe económica. Se determinó que la cobertura se entregaría en relación a los montos involucrados y no por una patología, fijándose también un deducible, por sobre el cual se accedería al pago total de la enfermedad. Esta iniciativa dio origen a la Cobertura para Enfermedades Catastróficas (CAEC), que fue regulada por la Superintendencia de ISAPRE, vigente hasta hoy con algunas modificaciones, su financiamiento está dado por el 7\% obligatorio.

FONASA tiene un porcentaje de adultos mayores 3 veces mayor que las ISAPRE; $56 \%$ de los afiliados FONASA completaron la educación escolar, versus 92\% de los afiliados ISAPRE; FONASA tiene una prevalencia $8 \%$ mayor de afiliados con 1 o más enfermedad crónica (21).

Este período de re-democratización coincide contradictoriamente con el "ajuste y cambio estructural" que los gobiernos comprometieron con los organismos financieros internacionales (es la época de "Invertir en Salud" informe conjunto de la OMS y el BM de 1993). Por ende las reformas sociales y de salud no fueron tales, meras adaptaciones neoliberales al nuevo escenario. El derecho a la salud en todo momento se encuentra cuestionado o a lo menos transformado discursivamente a un derecho a consumir tratamientos de las enfermedades.

\section{REFORMA AUGE (ACCESO UNIVERSAL CON GARANTÍAS EXPLÍCITAS)}

Este es el período más decadente de la medicina social chilena, ya que en neodemocracia sus líderes abandonaron el discurso más radical porque asumieron cargos en el gobierno y postergaron la discusión de las causas de las causas: estructura clasista del SSS y de la propia organización sanitaria. Se cristalizó así un sistema de atención a la enfermedad fragmentado: público cada vez más liberalizado y con una crónica falta de recursos humanos y materiales; privado neoliberal que se resiste ferozmente a las regulaciones; FFAA intocable (2). Esta situación no cambió con la reforma instalada en los 2000, al contrario, hubo una expansión del mercado privado, instalándose un modelo liberal completo, en donde el sector público funciona como un reaseguro de la población rica. Aquello reforzó la imagen actual de Chile como modelo para los países de la región e hizo más tentadora su "exportación" con el auspicio del Banco Mundial y otras agencias internacionales.

En los primeros años del 2000, se dio una actualización de la discusión ideológica y técnica acerca del aseguramiento de la salud en Chile, y se abrió una ventana de esperanza que resultó ser nada más que un espejismo (25). Eran tiempos de ideas como la separación de funciones o el pluralismo estructurado, reforzamiento de derechos individuales y de mercado y de ofertas de planes básicos asociados a la capacidad de compra.

El gobierno de Ricardo Lagos (2000 - 2006) estableció los “Objetivos sanitarios de la década 2000-2010”, paralelamente comenzó a diseñar la Reforma, que se expresó en el envío al parlamento de un conjunto de proyectos de Ley. La tarea de operacionalizar las políticas de gobierno, generar los proyectos de ley y realizar los estudios técnicos necesarios, recayó en el Comité Interministerial 
de la Reforma (Ministerio de Salud, de Hacienda, Secretaría General de la Presidencia, de Planificación, y Ministerio del Trabajo). Este comité, a su vez, constituyó una Comisión Ejecutiva del Proyecto de Reforma en Salud (CERS), desde la que fluyó la mayor parte del discurso oficial, lo cual no dejó de generar malestar en el MINSAL. Los gobiernos de la Concertación previos intentaron remediar la situación de salud (inequitativa, ineficiente, insatisfactoria para la gente), a través de más recursos para mejorar infraestructura y en parte la situación de los RRHH, sin modificar el modelo establecido en dictadura (26).

Mientras la ministra de salud, Michelle Bachelet, señalaba que la salud es una construcción social y para eso es indispensable que todos los actores sean parte de la reforma, además se insistía en que las personas tienen mucho que decir respecto de su salud y deben existir los espacios y canales que les permitan manifestar sus inquietudes y opiniones, las que deben ser tomadas en cuenta al adoptar definiciones sociales; el debate se hacía confuso ya que desde el MINSAL, así como de la CERS, se difundían o filtraban, múltiples documentos de trabajo (muchos con la advertencia "no citar") que apuntaban hacia la liberalización del sistema público, evidenciando las contradicciones y la falta de claridad en el proceso de diseño de la reforma. Hubo un doble liderazgo al interior del sector (MINSAL v/s CERS) en la discusión y formulación de la reforma. Esa bicefalia fue un signo más de la contradicción ideológica interna del gobierno. (2).

\section{Tabla 6: Trayectoria de la Reforma "Laguista" AUGE}

\begin{tabular}{|c|c|}
\hline Año & Transformación \\
\hline 1994-1999 & $\begin{array}{l}\text { Se confiere a FONASA función de gestionar el Seguro Social Público de Salud, a la fecha más de } \\
10,4 \text { millones de beneficiarios. Se promulga la Ley } 19.650 \text { que perfecciona funciones del Seguro } \\
\text { Público de Salud para compra en el sector privado en la MAI. Se crea el sistema de Pago por } \\
\text { Prestaciones Valoradas (PPV) para los hospitales y los Programas Especiales para disminuir listas } \\
\text { de espera, comparando servicios a prestadores privados con fines de lucro (2) }\end{array}$ \\
\hline 2000 & $\begin{array}{l}\text { Se definen los Objetivos Sanitarios para el decenio (27), situación que no ocurría desde la década } \\
\text { del } 60 \text { del siglo XX }\end{array}$ \\
\hline \multirow[t]{2}{*}{2003} & $\begin{array}{l}\text { Ley de Financiamiento de Reforma } \\
\text { Establece el financiamiento necesario para asegurar los objetivos sociales prioritarios del Gobierno, } \\
\text { a través del } 1 \% \text { de aumento del Impuesto al valor agregado (IVA) (28) }\end{array}$ \\
\hline & $\begin{array}{l}\text { Ley de Solvencia de ISAPRE } \\
\text { Asegura la estabilidad del sistema y protege a los afiliados }\end{array}$ \\
\hline \multirow[t]{2}{*}{2004} & $\begin{array}{l}\text { Ley de Autoridad Sanitaria y Gestión(29) } \\
\text { Modifica el Decreto Ley No } 2.763 \text {, de } 1979 \text {, con la finalidad de establecer una nueva concepción de } \\
\text { la autoridad sanitaria, distintas modalidades de gestión y fortalecer la participación ciudadana } \\
\text { Separa las funciones de provisión de servicios sanitarios y regulación del sector, fortalece la autoridad } \\
\text { sanitaria, se crean Subsecretarías de Salud Pública (bienes públicos) y de Redes Asistenciales (daño) } \\
\text { Creación de la Superintendencia de Salud (SIS) y de los Hospitales Autogestionados en red (EAR). } \\
\text { Se establece el funcionamiento del Consejo de Integración de la Red Asistencial (CIRA) que debe } \\
\text { ser liderado por los Directores de Servicios de Salud Locales (SNSS) } \\
\text { Crea un sistema de acreditación de prestadores públicos y privados }\end{array}$ \\
\hline & $\begin{array}{l}\text { Ley del Régimen General de Garantías en Salud (30) } \\
\text { Establece un régimen de garantías en salud: acceso, oportunidad, protección financiera y calidad } \\
\text { (Plan AUGE) }\end{array}$ \\
\hline
\end{tabular}

ISSN 1982-8829 Tempus, actas de saúde colet, Brasília, 13(2), 177-203, jun, 2019. 


\begin{tabular}{|l|l|}
\hline 2005 & $\begin{array}{l}\text { Ley de ISAPRES: } \\
\text { Modifica Ley no }^{\circ} 18.933 \text { (31), sobre Instituciones de Salud Previsional. También mejora transparencia } \\
\text { y rol de la Superintendencia de Salud }\end{array}$ \\
\hline 2012 & $\begin{array}{l}\text { Ley de Derechos y Deberes (32).Regula los derechos y deberes que tienen las personas en relación } \\
\text { con acciones vinculadas a su atención en salud }\end{array}$ \\
\hline
\end{tabular}

Fuente: Elaboración Propia

Por otra parte, encontramos (25) que desde una primera propuesta de financiamiento totalmente solidario (Fondo Único, todas las cotizaciones obligatorias -7\% del sueldo- más aportes Estatales), pasó a una solidaridad "parcial" (sólo un 3\% de las cotizaciones) y llegó a nada. El proyecto de solidaridad se abandonó y la reforma quedó transformada en un conjunto de proyectos de ley que dan cuenta de transformaciones administrativas y de los mecanismos de pago financiados por el aumento del IVA, manteniendo la falta crónica de universalidad. Los indicios apuntan a que esta situación se produjo por la presión del grupo de ISAPRE y del poder económico que representan, en un contexto de división política de la Concertación (progresistas y liberales) y de falta de movilización de la sociedad civil en defensa del proyecto solidario.

La "joya de la Corona" de la reforma fue entonces el Sistema de Acceso Universal con Garantías Explícitas (AUGE) o Garantías Explícitas en Salud (GES), que es un sistema de priorización, que incorporó la obligación legal de entregar una cobertura de acceso obligatoria para los eventos de salud-enfermedad priorizados, en FONASA e ISAPRE (BCN, 2004b).Se excluyeron las FFAA y el Seguro Laboral, por tanto, se constituye en una reforma de segunda generación prototípica (7).

La industria ISAPRE logró que el GES fuera considerado como un gasto extra por lo que era necesario aumentar los precios de los planes (prima plana GES); además se creó un fondo interISAPRE para compensar los riesgos. Desde 1990 al 2015 los precios de las primas han aumentado 3,5 veces en precios reales. Cerca del $47,3 \%$ de usuarios son cautivos de su aseguradora (12).

Al tratarse de un mecanismo de priorización y focalización, el AUGE-GES ha implicado la segmentación de la población de acuerdo a si tiene o no los requisitos para ser beneficiada por este plan. Por otra parte, para los establecimientos públicos, especialmente hospitalarios, las atenciones AUGE-GES son casi completamente financiadas por el Estado, generándose así un incentivo para que la producción de servicios esté fundamentalmente orientada a las patologías AUGE-GES. Es así como, estas segmentaciones atentan contra la integralidad y universalidad pretendida por el sistema, ya que se generan restricciones a la garantía de acceso por factores como el sexo, edad o la severidad de la enfermedad. 
Tabla 7: Consecuencias del sistema de priorización AUGE-GES

\begin{tabular}{|c|c|}
\hline Consecuencias Positivas & Consecuencias Negativas \\
\hline $\begin{array}{l}\text { - Mejoría en el acceso a la atención en eventos GES } \\
\text { - Satisfacción de las personas con eventos GES } \\
\text { - Mejoramiento de la gestión clínica en general } \\
\text { - Mejoramiento del funcionamiento en red para } \\
\text { - eventos GES } \\
\text { - Mejoramiento de los sistemas de OIRS } \\
\text { - Aumento de la inversión en equipamiento en sector } \\
\text { público }\end{array}$ & $\begin{array}{l}\text { - "Augización” de la atención en los tres niveles } \\
\text { - Listas de espera GES } \\
\text { - Listas de espera No GES } \\
\text { - Entrega no oportuna de algunos medicamentos de la } \\
\text { - canasta AUGE } \\
\text { - Despriorización de la Promoción y Prevención en APS } \\
\text { - Insuficiente inversión en infraestructura y equipamiento } \\
\text { - Aumento de las transferencias de dinero desde el sector } \\
\text { - } \text { público al privado } \\
\text { - Aumento de las primas en ISAPRE } \\
\text { - Pérdida de "libertad de elección" en ISAPRE }\end{array}$ \\
\hline
\end{tabular}

Fuente: Elaboración Propia a partir de:33, 34, 35, 36, 37, 38, 39,40, 41, 42.

\section{NUEVAS PROPUESTAS DE CAMBIO ESTRUCTURAL}

Desde 1990 a 2018 las propuestas de cambios estructurales al sistema de aseguramiento financiamiento han sido múltiples, fluctuando desde la mirada Liberal hasta la del Bienestar.

Tabla 8: Propuestas de instituciones de cambio estructural 1996 - 2018

\begin{tabular}{|c|c|}
\hline $\begin{array}{l}\text { Liberales - Neoliberales } \\
\text { Multi Seguros }\end{array}$ & $\begin{array}{c}\text { Seguridad Social Salud (SSS) } \\
\text { Seguro Único - Sistema Nacional de Salud }\end{array}$ \\
\hline $\begin{array}{l}\text { Creación de un fondo de "ahorro" a partir de } \\
\text { un } 0,9 \% \text { de la cotización obligatoria (43) }\end{array}$ & $\begin{array}{l}\text { Creación del Fondo Único Solidario (Seguridad Social } \\
\text { Bismarkiana) } \\
\text { - Gobierno Concertación } 2000 \text { (54) } \\
\text { - Fundación Equidad (55) } \\
\text { - Federación Nacional de Profesionales Universitarios de } \\
\text { los Servicios de Salud (56) }\end{array}$ \\
\hline $\begin{array}{l}\text { Creación de mercado de seguros competitivos } \\
\text { - "Grupo de los } 13 \text { " }(44) \\
\text { - Colegio Médico AG }(45,46) \\
\text { - Asociación de Isapres }(47) \\
\text { - Altura Management }(48) \\
\text { - Asociación de Economía de Salud de Chile } \\
(49)\end{array}$ & $\begin{array}{l}\text { Creación de un Sistema Nacional de Salud } \\
\text { (Seguridad Social Bedveridgiana) } \\
\text { - Asociación Latino Americana de Medicina Social, } \\
\text { ALAMES - Chile (17) }\end{array}$ \\
\hline $\begin{array}{l}\text { Creación de Multiseguros Público-Privados } \\
\text { con Plan de Salud Único/Mínimo/Garantizado } \\
\text { - Comisión Asesora Presidencial 2010, (50) } \\
\text { - Comisión de Partidos Políticos } 2010(51) \\
\text { - Pontificia Universidad Católica (19) } \\
\text { - Butelmann et al. (52) } \\
\text { - Instituto de Salud Pública de la Universidad } \\
\text { Nacional Andrés Bello (53) }\end{array}$ & $\begin{array}{l}\text { Aumento del Aporte Fiscal a un 6\% deI PIB } \\
\text { (Seguridad Social Bismarkiana) } \\
\begin{array}{l}\text { - Federación Nacional de Profesionales } \\
\text { Universitarios de los Servicios de Salud (57) } \\
\text { - Agrupación Nacional de Médicos de Atención } \\
\text { Primaria (58) }\end{array}\end{array}$ \\
\hline
\end{tabular}

ISSN 1982-8829 Tempus, actas de saúde colet, Brasília, 13(2), 177-203, jun, 2019. 


\begin{tabular}{|l|l|}
\hline & $\begin{array}{l}\text { Creación de un Seguro Único } \\
\text { (Seguridad Social Bismarkiana) }\end{array}$ \\
- Iniciativa Ciudadana Salud Justa (59) \\
- Comisión de Salud Revolución Democrática (60) \\
- Fundación Creando Salud (61) \\
- Salud por Chile (62) \\
- Comisión Asesora Presidencial 2014. (12) \\
$\begin{array}{l}\text { - Comisión Escuela de Salud Pública de la Universidad de } \\
\text { Chile - Colegio Médico AG (21) }\end{array}$ \\
\hline
\end{tabular}

Fuente: Elaboración Propia

Las últimas surgen como respuesta a una Sentencia sin precedentes del Tribunal Constitucional - TC (63) que señaló, ante la alta y persistente judicialización de las ISAPRE, que estas funcionaban fuera de la Constitución ya que al discriminar por sexo y edad a sus afiliados/as (Tablas de factores de riesgo), estaban contraviniendo el Derecho a la Seguridad Social (Artículo 19, $\mathrm{N}^{\circ} 18$ ), no el Derecho a la Salud, que explícitamente prohíbe todo tipo de discriminación.

Figura 2: Esquema de Propuestas de Reforma Estructural y funcional de la SSS en neodemocracia

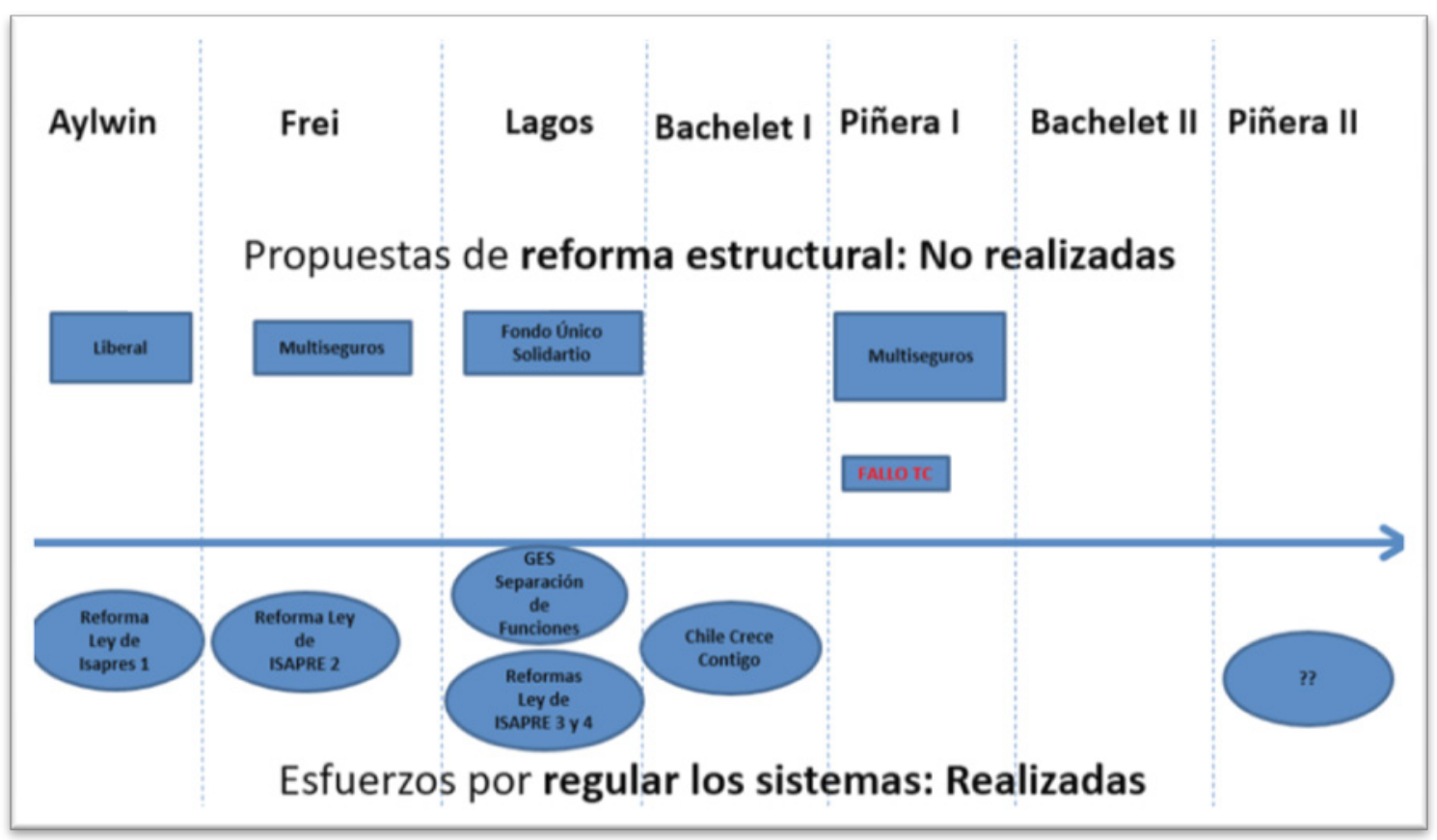

Fuente: Elaboración Propia a partir de: 44, 17, 12, 21.

El Proyecto de Ley enviado por Piñera I, establecía un fondo de compensación, para asegurar un Plan Garantizado de Salud (PGS - AUGE ampliado), por unas nuevas entidades de la seguridad social que pasarían a ser las ISAPRE y el FONASA, pero este último solo en su segmento de cotizantes reales, vale decir que las personas sin ingreso del FONASA, quedaban fuera de la propuesta aunque sí son consideradas en el financiamiento (aporte fiscal). Cid et al. (19) señalan que "El sistema de financiamiento de salud chileno presenta problemas clásicos que se expresan en ausencia de regulación económica adecuada que derivan en discriminación, retroalimentan la inequidad y redundan en pérdidas sociales evitables. Se trata de un problema estructural en Tempus, actas de saúde colet, Brasília, 13(2), 177-203, jun, 2019. ISSN 1982-8829 
el diseño y arreglo institucional del financiamiento y del seguro, que conducen a inequidades en el acceso y uso de los recursos, el que traba el desarrollo del sistema. En estas condiciones, el sistema está en constante desequilibrio y cuestionado en cuanto a su viabilidad", Chile es el país más alejado del esquema promedio de distribución del financiamiento de los países OCDE. Se caracteriza por el alto financiamiento privado y dentro de ello, por ostentar el gasto de bolsillo más alto de la OCDE. Cerca del 18\% de la población gasta 2,4\% del PIB en Salud. El otro cerca de $82 \%$ gasta el 4,5\% del PIB. Si hiciéramos una relación directa, los beneficiarios FONASA deberían gastar cerca del 11\% del PIB para estar en iguales condiciones que los de ISAPRE. Terminan concluyendo que se requiere un sistema multiseguros con un "fondo de mancomunación de recursos y riesgos, a través del aporte del 7\% obligatorio a un fondo central, a lo que se agregan los aportes fiscales necesarios. Este procedimiento se complementa con la entrega de recursos desde dicho fondo a aquellas aseguradoras que han incurrido en costos superiores al promedio, extrayéndolos de las otras aseguradoras con menores costos, lo que permite concretar la solidaridad y mitigar los incentivos a la discriminación, junto con ayudar a la contención de costos". Esta salida denominada como funcional adolece de problemas importantes ya que solo mitiga los incentivos a la discriminación y abre la puerta para que parte del financiamiento fiscal se utilice para financiar aseguradoras privadas vía fondo mancomunado, además de no pronunciarse respecto a la legalidad de lucrar con los recursos de la seguridad social.

La propuesta de algunos gremios ha sido consistente en expresar la necesidad de mejorar el financiamiento por la vía de impuestos generales y del aumento del \% PIB destinado a salud, con disminución del gasto de bolsillo $(57,58,64)$.

En un estudio del MINSAL (65), 31\% está de acuerdo con la frase "Nuestro sistema de salud tiene muchas cosas malas y tenemos que reconstruirlo por completo". Los usuarios de FONASA indican que lo positivo del seguro es la gratuidad para personas que no tienen como pagar, y lo negativo es la falta de especialistas. Por el contrario, los usuarios de ISAPRE indican que lo positivo es la variedad de especialistas y lo negativo es el alza de sus planes. La principal razón de sensación de desprotección en FONASA es la calidad del sistema y entre los de ISAPRE el costo de las atenciones y su cobertura. Se observa una baja significativa en la tenencia de otro seguro de salud privado complementario entre los usuarios de ISAPRE. La satisfacción es mayor entre usuarios del AUGE respecto de los no usuarios (No GES). En relación a la imagen de las instituciones, FONASA es considerada como la institución más accesible y cercana a las personas. Ante la pregunta de si estaría dispuesto a pagar mayores impuestos por mejorar el nivel de atención de las personas, un $31 \%$ declara estar bastante o muy dispuesto, mientras un $42 \%$ señala estar bastante o muy indispuesto (65). Por otra parte, "Los derechos aparecen como una voz tenue en los discursos de la ciudadanía recopilados en el marco de este estudio realizado en 2017 y 2018”, "Los derechos se poseen, pues están escritos, pero son percibidos como letra muerta", "hay una dicotomía entre un discurso que concibe a los derechos como aquellos relativos en su calidad de consumidores versus la percepción de los derechos ciudadanos: si se paga, hay mayor posibilidad de exigir el derecho; en cambio, no se reconoce esta facultad en el ámbito público-gratuito, en donde las prestaciones

ISSN 1982-8829 Tempus, actas de saúde colet, Brasília, 13(2), 177-203, jun, 2019. 
son concebidas antes como favores, beneficios, y no como derechos adquiridos y legítimamente ejercidos, además de financiados por la población”. (64).

La Propuesta del COLMED-ESP (21) tiene como objetivo "proponer una reforma estructural del financiamiento del sistema de salud, orientada por los principios de la seguridad social y el derecho a la salud, que integre los sectores público y privado, con una perspectiva de largo plazo para el fortalecimiento del sistema"; y presenta como particularidad que, junto a la de ALAMES (17), incluye a las FFA dentro del rediseño. Se propone un Plan Universal de Salud, para todas y todos las personas en territorio nacional, aumento en la protección financiera (especial énfasis en medicamentos) y mecanismos que permitan empoderar a los ciudadanos en relación con el derecho a la salud, entre otras medidas.

\section{Figura 3: Propuesta de Reforma Estructural COLMED-ESP}

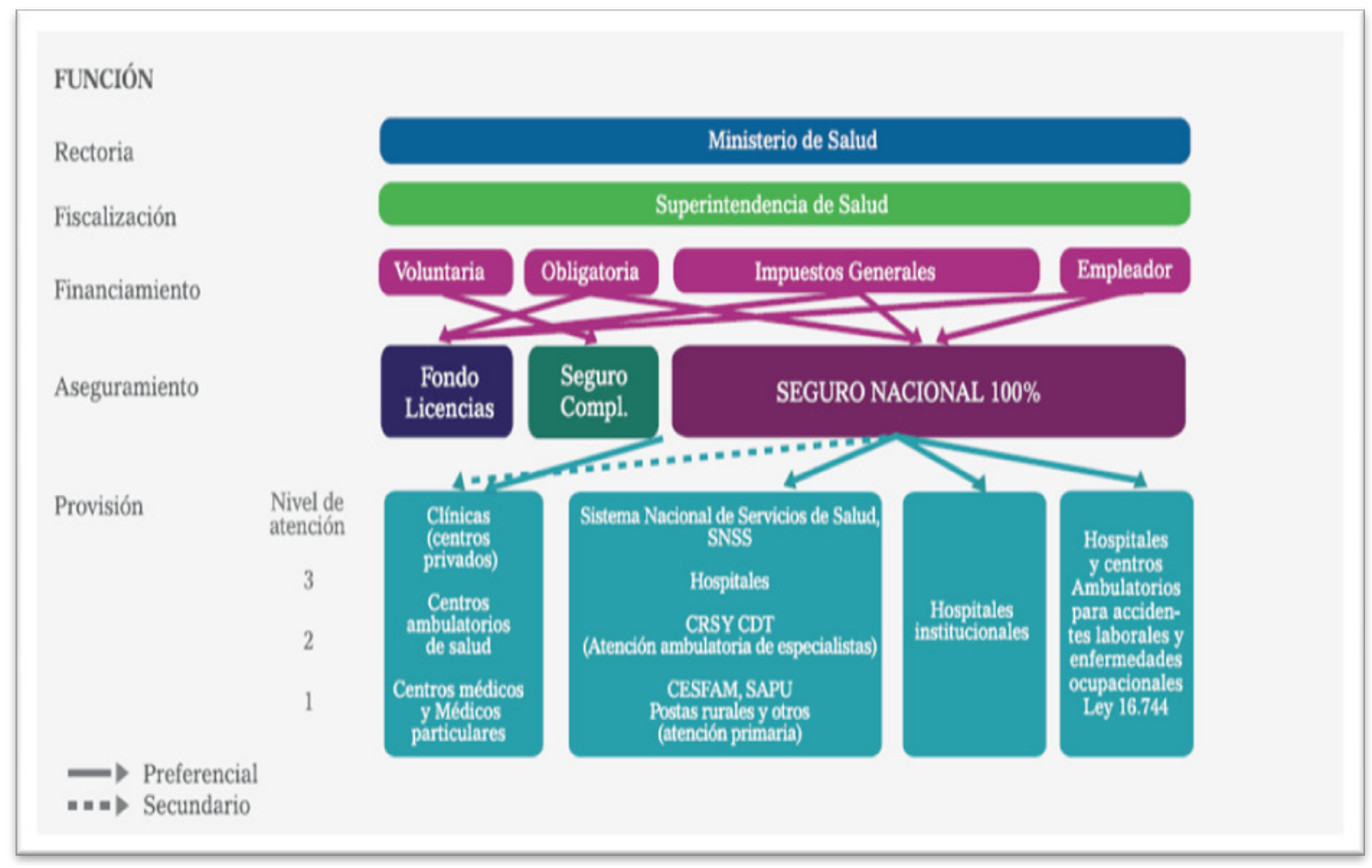

Fuente: Frenz et al. (21)

\section{CONCLUSIONES}

A modo de síntesis, podemos retomar la discusión acerca de cada período histórico considerado y las dimensiones explicativas de la hipótesis. A principios del siglo XX, la organización del movimiento popular en torno a las mutuales y la comprensión de una parte de la élite acerca de la importancia de intervenir sobre las condiciones sanitarias de la población pobre, favorecieron la implementación de la SSOO, pionera en su tipo por la intervención del Estado en la asistencia médica. Luego, a mediados de siglo, la consolidación del SNS fue alimentada por la presión de parlamentarios a fines a los principios de la medicina social, pero perjudicada por el contexto de guerra fría de la época y la influencia estadounidense en América Latina. Posteriormente, la 
perpetuación clasista de la SSS fue más nítidamente implementada en la Ley de Medicina Curativa, apoyada por el gremio médico organizado y los sectores medios de la población. Por otra parte, los resultados devastadores de la dictadura fueron propiciados por un contexto socio-político autoritario sin posibilidad de movilización social opositora, exclusividad de los militares como únicos sujetos definidores de las reformas, y contenidos decididamente privatizadores, como en la Constitución de 1980. Ya en la pos dictadura, la posibilidad de reformas equitativas fue sofocada por la desmovilización social heredada y por la hegemonía de los valores neoliberales. Además, los sectores políticos de izquierda con representación en el congreso nacional pactaron el contenido de las políticas sociales con la derecha, como consecuencia de los enclaves autoritarios que caracterizaron a la transición política chilena (senadores designados, fuerzas armadas como garantes de la institucionalidad, sistema electoral binominal, entre otros).

La estratificación clasista neoliberal de la sociedad, de acuerdo a criterios puramente monetarios, y la instauración de un mercado consumista al que se puede acceder no sólo a través de ingresos sino también a través del crédito, significa para muchos chilenos/as especialmente de "clase media", sentir al consumo como único medio de progreso y expresión de la identidad. De esta forma se ha dado un disciplinamiento y despolitización de la ciudadanía (66). El consumo se vive, como una compensación, una evasión, cuando se ha perdido la esperanza en un mundo mejor (67). En salud, los principales efectos de este contexto, sumado a la política de acuerdos emprendida por los gobiernos de la Concertación de Partidos por la Democracia (1990 - 2010) y la Nueva Mayoría (2014 - 2018), no fueron menores y significaron en la práctica la mantención de las estructuras y formas de actuar en salud dejadas por la dictadura, denominadas ahora como "Modernizaciones en Democracia".

En Chile, la elite política y el 20\% más rico de la población está en ISAPRE, con muy pocos incentivos para el cambio (clasismo) por ende nos encontramos muy lejos de la recomendación de la Comisión de Salud Global del Lancet (68): "Los gobiernos nacionales deben invertir en sistemas de salud de alta calidad para su propia gente y hacer que dichos sistemas sean responsables ante las personas a través de la legislación, la educación sobre los derechos, la regulación, la transparencia y una mayor participación pública. Los países sabrán que están en el camino hacia un sistema de salud responsable y de alta calidad cuando los trabajadores de la salud y los responsables de la formulación de políticas elijan recibir atención médica en sus propias instituciones públicas".

Junto con Alicia Stolkiner (69) estamos convencidos que se requiere analizar crítica y constantemente los discursos sociales, para que el debate empodere al movimiento social y se construyan prácticas contra-hegemónicas y demandas por una SSS realmente justa, igualitaria y solidaria, "promover una praxis que despliegue la potencialidad de construir y ejecutar nuevas formas de abordar colectiva y solidariamente los procesos de salud-enfermedad-cuidado".

La fragmentación clasista de los sistemas sanitarios, ha sido impermeable a concepciones más verdaderamente cercanas a los principios de la seguridad social, es lo que denominamos como

ISSN 1982-8829 Tempus, actas de saúde colet, Brasília, 13(2), 177-203, jun, 2019. 
"enfermedad socialmente transmisible". Ya que se ha transmitido - construido societariamente sin que aún se haya podido generar un "remedio" para detener su propagación histórica. Hubo momentos en que la esperanza de mejoría fue fuerte, como cuando se discutía la creación de un Sistema Nacional de Salud (1950), o cuando se proponía un sistema Único de Salud (1970) o un Fondo Único solidario (2000). Sin embargo, la "enfermedad" persiste y presenta reagudizaciones como en el actual período de gobierno de derecha $(2018-2022)$.

Finalmente vemos que las transformaciones necesarias en la SSS en Chile, van de la mano de dejar atrás los valores neoliberales (individualismo diferenciador aspiracional, competitividad agresividad, hedonismo sin sublimación, caridad, libertad de elección, desconfianza - inseguridad, desidia - desesperanza - impunidad), y re-tomar los valores culturales del Buen Vivir: cooperación, solidaridad, confianza, comunidad, respeto,compromiso, legitimidad de1@s otr@s, compasión.

\section{Contribuição dos autores:}

Mario Parada-Lezcano: autor principal, concepción, delineamiento, ejecución del trabajo, análisis de los datos, redacción y aprobación final del manuscrito.Fabián Moraga-Cortés: co-autor, ejecución del trabajo, análisis de los datos y redacción).

\section{REFERENCIAS}

1. Labra, María Eliana. Política, saúde e intereses médicos no Chile (1900-1990). Tesis doctoral. Mimeo. Instituto Universitario de Investigación IUPERJ. Río de Janeiro.1998.

2. Parada, Mario.Evolución del Sistema de Protección de la salud en Chile: un análisis sociológico". Tesis Doctoral. Departamento de Sociología Universidad Autónoma de Madrid. Diciembre de 2004.

3. García, Juan. Pensamiento social en salud en América Latina. 1994. Interamericana McGraw - Hill - OPS. México.

4. Paim, Jairnilson y Almeida Filho, Naomar (1998): Saúde coletiva: uma "nova saúde pública" ou campo aberto a novos paradigmas? Rev. Saúde Pública, 32 (4): 299-316

5. Rojas, Francisco y Márquez, Miguel (compiladores) (2009): ALAMES en la Memoria. Selección de lecturas. ALAMES, Cuba, y Editorial Caminos, La Habana.

6. Granda, Edmundo. La Salud y la Vida (I). Organización Panamericana de la Salud/ Organización Mundial de la Salud, Ministerio de Salud Pública, Consejo Nacional de Salud, Consejo Nacional de Educación Superior, Universidad de Cuenca, Universidad Nacional de Loja, y Asociación Latinoamericana de Medicina Social. 2009 
7. Tetelboin, Carolina. Tendencias y contratendencias en el Sistema de Salud de Chile en el marco de la situación regional. En, Por el derecho universal a la Salud. Tetelboin, Carolina y Laurell, Asa (Coord.) 2015. CLACSO - Universidad Autónoma Metropolitana. México. Hallado en enero 2019:http://biblioteca.clacso.edu.ar/clacso/gt/20151109090721/derecho_universal_a_la salud.pdf

8. Labra, María Eliana (2002): La reinvención neoliberal de la inequidad en Chile. El caso de la salud. CadSaúde Pública. Río de Janeiro. 18(4):1041-1052

9. Illanes, María. En el nombre del pueblo, del estado y de la ciencia: historia social de la salud pública, Chile, 1880-1973: hacia una historia social del Siglo XX. 1993. Santiago de Chile. Colectivo de Atención Primaria.

10. Molina, Carlos (2010): Institucionalidad sanitaria chilena 1889-1989. LOM Ediciones.

11. Constitución Política de la República de Chile. 1980. Hallado en enero 2019: https://www. camara.cl/camara/media/docs/constitucion_politica.pdf

12.Cid, Camilo; Aguilera, Ximena; Arteaga, Óscar, Soledad Barría, Pedro Barría, Carmen Castillo, David Debrott, Marcelo Dutilh, Pedro García, Tomás Jordán, Osvaldo Larrañaga, Fernando Matthews, Mario Parada, Guillermo Paraje, Orielle Solar y Andras Uthoff. Informe final. Comisión asesora presidencial para el estudio y propuesta de un nuevo régimen jurídico para el sistema de salud privado. 2014. 2a Edición. 2016. Hallado en enero 2019: https://www. minsal.cl/wp-content/uploads/2016/05/INFORME-FINAL COMISION-PRESIDENCIALISAPRES.pdf

13. Homedes, N. y Ugalde, A. Privatización de los servicios de salud: las experiencias de Chile y Costa Rica. GacSanit 2002;16(1):54-62

14. Tetelboin C. Granados JA. Las ISAPRES y su impacto en el sistema de salud chileno. Salud y Problema (México) 1999 diciembre; 4(7): 7-15.

15. Oyarzo, Cesar. La descentralización financiera en Chile en la década de los noventa. Revista Panamericana de Salud Pública, Washington, v. 8, n. 1, p. 72-82, 2000

16. Böhm, Katharina; Schmid, Achim; Götze, Ralf; Landwehr, Claudia; Rothgang, Heinz (): Classifying OECD healthcare systems: A deductive approach, TranState Working Papers, No. 165. 2012. Halladoenenero 2019: https://www.econstor.eu/handle/10419/64809

17. Parada, Mario; Ibacache, Carolina; Santana, Paula y Medina, Sebastián. Informe de salud en Chile. En "La lucha por el derecho a la salud en América Latina. ALAMES, 30 años de lucha". Asociación Latinoamericana de Medicina Social - People'sHealthMovement - Movimiento por la 
Salud Dr. Salvador Allende. Capítulo 2. El Salvador. 2014. ISBN 978-99923-27-84-5 Hallado en enero 2019: http://www.alames.org/index.php/documentos/libros/medicina-social/libros-1/58-lalucha-por-el-derecho-a-la-salud-en-ame-rica-latina/file

18. BCN - Biblioteca Congreso Nacional. Ley 19.465 que Establece Sistema de Salud para las Fuerzas Armadas. [Online]. 1996. Hallado en enero 2019: https://www.leychile.cl/ Navegar?idNorma $=30832$

19. Cid, Camilo; Torche, Arístides; Bastías, Gabriel; Herrera, Cristián y Ximena Barrios. Bases para una reforma necesaria al seguro social de salud chileno. En Propuestas para Chile, Concurso Políticas Públicas. 2013. Pontificia Universidad Católica de Chile. Hallado en enero 2019: https://politicaspublicas.uc.cl/wp-content/uploads/2015/02/propuestas-para-chile-2013capitulo-v.pdf

20. Cid, Camilo. Financiamiento Agregado de la Salud en Chile: Año 2008. CuadMédSoc (Chile) 2011, 51(3): 143-150

21. Frenz, Patricia; Siches, Izkia; Aguilera, Ximena; Arteaga, Óscar; Cid, Camilo; Estay, Roberto; Galleguillos, Sylvia; Oyarzún, Ricardo; Parada, Mario; Uthoff, Andras; Vega, Jeannette. Propuestas para una Reforma Integral al Financiamiento de la Salud en Chile. Escuela de Salud Pública, Universidad de Chile, Colegio Médico de Chile A.G. 2018. Hallado en enero 2019: http://www.colegiomedico.cl/wp-content/uploads/2018/05/Propuesta-Reforma-deFinanciamiento-Integral-a-la-Salud.pdf

22. OECD. Health at a Glance 2017. Hallado en enero 2019: https://www.oecd.org/els/healthsystems/Health-at-a-Glance-2017-Chartset.pdf

23. Cid Pedraza C, Matus-López M, Báscolo E. Espacio fiscal para salud en las Américas: ¿es suficiente el crecimiento económico? RevPanam de Salud Publica. 2018;42:e86. https://doi. org/10.26633/ RPSP.2018.86

24. Debrott, David. Sistema de salud chileno: funcionamiento, problemáticas y propuestas de reforma. En Diego Calderón y Felipe Gajardo (Comps.) Chile del Siglo XXI: Propuestas desde la Economía. Ediciones Böll y Estudios Nueva Economía. 2017. Hallado en enero 2019: https:// cl.boell.org/sites/default/files/chile_del_siglo_xxi_propuestas_desde_la_economia_final.pdf

25. Parada, Mario. Financiamiento solidario: un espejismo en la reforma sanitaria chilena. CuadMedSoc (Chile); 2005, 45: 138-143

26. CERS. Estudio cualitativo acerca de la reforma de salud. Comisión Ejecutiva de la Reforma de Salud. 2000. Mimeo. Santiago. 
27. Ministerio de Salud - MINSAL. Objetivos Sanitarios de la década 2000-2010 [Online]. 2006. Hallado en enero 2019: http://www.bibliotecaminsal.cl/wp/wp-content/uploads/2016/03/5. pdf

28. BCN - Biblioteca del Congreso Nacional. Ley 19.888 que establece financiamiento necesario para asegurar los objetivos sociales prioritarios del gobierno. [Online]. 2003. Hallado en enero 2019: https://www.leychile.cl/Navegar?idNorma=213493

29. BCN - Biblioteca Congreso Nacional. Ley 19.937 que establece una nueva concepción de la autoridad sanitaria, distintas modalidades de gestión y fortalecer la participación ciudadana. [Online]. 2004. Hallado en enero 2019: https://www.leychile.cl/Navegar?idNorma=221629

30. BCN - Biblioteca Congreso Nacional. Ley 19.966 que establece un régimen de garantías en salud. 2004. Hallado en enero 2019: https://www.leychile.cl/Navegar?idNorma=229834

31. BCN - Biblioteca Congreso Nacional: Ley 20.015 que modifica la ley No 18.933, sobre instituciones de salud previsional. [Online]. 2005. Hallado en enero 2019: https:/www.leychile. $\underline{\mathrm{cl} / \text { Navegar?idNorma }=238102}$

32. BCN - Biblioteca Congreso Nacional. Ley 20.584 que regula los derechos y deberes que tienen las personas en relación con acciones vinculadas a su atención en salud. [Online]. 2012. Hallado en enero 2019: https://www.leychile.cl/Navegar?idNorma=1039348

33. Méndez C, Miranda C, Torres M, Márquez M, Matthews T. Implementación de la política de Hospitales Autogestionados en Chile: percepción de los profesionales hospitalarios. RevChil Salud Pública 2012; Vol 16 (3): 247 - 255.

34. Núñez, Paulina; Méndez, Claudio. Implementación de la política nacional de medicamentos de la Reforma de Salud: percepción del profesional químico farmacéutico. RevChil Salud Pública 2011; Vol 15 (1): 21 - 28

35. Durán J, Méndez C. (2010): Implementación de la reforma de salud: percepción del profesional químico farmacéutico. Cuadernos Médico-Sociales de Chile; p. 124-131

36. Paraje, Guillermo y Vásquez, Francisco. Health equity in an unequal country: the use of medical services in Chile. International Journal for Equity in Health, 2012, 11:81

37. Valdivieso V, Montero L. El Plan AUGE: 2005 al 2009. Rev. Méd. Chile v.138 n.8 Santiago ago. 2010; p. 1040-1046

38. Bitrán R, Escobar L, Gassibe P. (2010): After Chiles Health Reform: Increase in coverage and access decline in hospitalization and death rates. Health Affairs; p. 2161

ISSN 1982-8829 Tempus, actas de saúde colet, Brasília, 13(2), 177-203, jun, 2019. 
39. Parada, Mario; Reyes, Carolina; Cuevas, Katherine; Ávila, Antonio; López, Paulina; et al. Transformaciones del sistema de salud público post reforma AUGE-GES en Valparaíso. Revista Chilena de Salud Pública; 2014, Vol 18 (2): 127-139

40. Parada, Mario; Reyes, Carolina; Cuevas, Katherine; Ávila, Antonio; Paulina López, et al. Cambios en la Estructura Organizacional del Sistema de Salud Público post reforma del 2004 en Valparaíso - Chile. Revista Salud Problema 2015; No 18 del año 9 de la Segunda Época. Julio diciembre de 2015. México DF - México.

41. Román O, Muñoz F. Una mirada crítica en torno al plan AUGE. Algunos aspectos generales y valóricos. Revista Médica de Chile; 2008. p. 1599-1603

42. Patty Fidelis de Almeida, Suelen Carlos de Oliveira, Lígia Giovanella. Integração de rede e coordenação do cuidado: o caso do sistema de saúde do Chile. Ciência\&SaúdeColetiva, 23(7):2213-2227, 2018

43. Sánchez, Héctor (1996): Una visión sobre la evolución de los sistemas de salud en la próxima década, en Giaconi, J. y Caviedes, R. (Eds.): Las Isapre: hacia la modernidad en salud, realidades, perspectivas y desafíos del sistema. Asociación de Isapre AG - CIEDESS. Santiago

44. Vergara, Marcos. Reforma del sector de la salud en Chile: Avances y problemas en la implementación. 2007. Hallado en enero 2019: http://www.salud-e.cl/wp-content/ uploads/2013/08/Reforma + del + sector + de + la + salud + en + Chile + Marcos + Vergara + Expansiva.pdf

45. Colegio Médico de Chile A.G. Humanizar la Salud en Chile, Propuesta del Colegio Médico de Chile A.G. a las autoridades que asumirán la presidencia de la República y Poder Legislativo de la Nación. Santiago. 2013. Hallado en enero 2019: http://www.colegiomedicovalparaiso.cl/ respaldo_sitio01/uploaded/Documento\%20completo.pdf

46. Colegio Médico de Chile A.G. Visión del Colegio Médico de Chile a la Comisión Presidencial de Salud. 2014. Hallado en enero 2019: http://archivospresidenciales. archivonacional.cl/uploads/r/archivo-presidencia-de-la-republica-2/e/3/4/ e34c4448bfa86b03e141fe894dc2087f27c2532014114cf25266e0b91cb30b69/ home aristoteles documentos Pre 7.pdf

47. Asociación de ISAPRES de Chile. Movilidad entre Isapres de beneficiarios con preexistencias. Santiago. 2014. Hallado en enero de 2019: http://isapre.cl/PDF/Movilidad\%20 mayo\%20PRENSA.pdf

48. Beaumont, Victoria. Consolidando la Seguridad Social en los Aseguradores Privados. Altura Management. 2014. Hallado en enero 2019: http://archivospresidenciales. archivonacional.cl/uploads/r/archivo-presidencia-de-la-republica-2/a/e/2/ 
ae2ed496c71268bf35c413a676a3b0665eec3d56e0c5a6ee3ceb0025492e5afb/ home aristoteles documentos_Pre_11.pdf

49. Vargas, Verónica. Regulación de las ISAPRES 2. Asociación de Economía de Salud de Chile. 2014. Hallado en enero 2019: http://archivospresidenciales.archivonacional.cl/uploads/r/ archivo-presidencia-de-la-republica-2/8/e/a/8ea4f0ebfcedfd34f4bb6b789646baab15a727b3a1b4 d5532d225f63bdb4382c/ home_aristoteles_documentos_Pre_12.pdf

50. Comisión Asesora Presidencial de Salud. (2010). Informe Comisión Presidencial de Salud. Santiago. Hallada en enero 2019: https://www.minsal.cl/portal/url/item/96c1350fbfla856 ce04001011f015405.pdf

51. SIS - Superintendencia de Salud. Proyecto Ley que Crea el Plan Garantizado de Salud en Isapres. Superintendencia de Salud. 2012. Hallado en enero 2019: http://www.supersalud.gob.cl/ prensa/672/articles-7410_ppt_1.pdf

52. Butelmann, Andrea; Duarte, Fabián; Nehme, Nicole; Paraje; Guillermo y Vergara, Marcos. Propuesta de Reforma al Sistema de Salud. Santiago. 2014. Hallado en enero 2019: https://www.espaciopublico.cl/wp-content/uploads/2016/05/30.pdf

53. Arredondo, Annabella; Bertoglia, María Paz; Inostroza, Manuel; Labbé, Javier; Lenz, Rony; Sánchez, Héctor. Construcción política del sistema de salud chileno: la importancia de la estrategia y la transición ¿Cuáles son nuestras verdaderas posibilidades de cambio? Instituto de SaludPública. Universidad Nacional Andrés Bello. 2017

54. Lagos, Ricardo. Discurso de inicio de la legislatura ordinaria en el congreso nacional. Presidencia de la República. Santiago de Chile. 2000. Hallado en enero 2019: https://www.

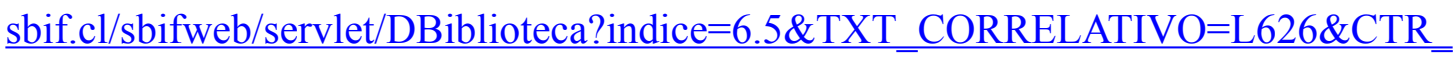
CORRELATIVO $=\mathrm{XXXXXXXXXXXXXXX}$

55. Lagomarsino, Tomás. Audiencia Comisión Presidencial para la Reforma del Sistema Privado de Salud. Fundación Equidad. 2014. Hallado en enero 2019: http:// archivospresidenciales.archivonacional.cl/uploads/r/archivo-presidencia-de-la-republica-2/4/a/ 0/4a099b1262f42c3c9a0ee521de953f720248864c22992ca87122ac4a215ddd2a/ home aristoteles_documentos_Pre 15.pdf

56. FENPRUSS. Hacia una cobertura universal en Salud. 2014. Hallado en enero 2019: http://archivospresidenciales.archivonacional.cl/uploads/r/archivo-presidencia-de-la-republica2/b/8/6/b869f7543b1191e1a25f61f3f289937bc814ab405f16eb5f53c007217c651acf/ home aristoteles_documentos_Pre_13.pdf

57. FENPRUSS. La Salud que Soñamos: Ideas para un Programa de Gobierno en Materia 
de Salud. Santiago. 2013. Hallado en enero 2019: https://issuu.com/fenpruss/docs/librillofenpruss-2013 baja

58. Bass Camilo. Atención Primaria de Salud oportuna y de calidad para un Chile del Siglo XXI. 2014. Hallado en enero de 2019:http://archivospresidenciales.archivonacional.cl/index.php/ presentacion-de-medicos-de-atencion-primaria-de-salud

59. Iniciativa Ciudadana Salud Justa. Salud Justa: una Iniciativa Ciudadana. 2013. Santiago. Hallado en enero 2019: https://saludjusta.wordpress.com/

60. Comisión de Salud Revolución Democrática. Reforma al Financiamiento del sistema de Salud. 2014. Hallado en enero de 2019: http://archivospresidenciales.archivonacional.cl/ uploads/r/archivo-presidencia-de-la-republica-2/7/3/c/73c15e0b413ec9eaee1a603289ee62ebe93a 29ec053c466338f50843281cc394/_home_aristoteles_documentos_Pre 17.pdf

61. Fundación Creando Salud. Propuestas para una reforma del aseguramiento en salud. Hacia una salud como derecho social. 2014. Hallado en enero 2019: http://archivospresidenciales. archivonacional.cl/uploads/r/archivo-presidencia-de-la-republica-2/0/c/5/0c51c280b56795d114e 7d93515188ae50ed705ebaa58c968697750148942ddd6/_home_aristoteles_documentos_Pre_21. pdf

62. Salud por Chile (2014): Audiencia ante la comisión asesora presidencial para el estudio y propuesta de un nuevo régimen jurídico para el sistema privado de salud. Hallado en enero de 2019: http://archivospresidenciales.archivonacional.cl/uploads/r/archivo-presidencia-de-larepublica-2/0/c/5/0c51c280b56795d114e7d93515188ae50ed705ebaa58c968697750148942d dd6/ home_aristoteles_documentos_Pre 21.pdf

63. Tribunal Constitucional. Sentencia recaída en rol $n^{\circ}$ 1710-10, proceso iniciado de oficio para decidir sobre la constitucionalidad del artículo 38 ter de la ley de Isapres. 2010. Hallado en enero 2019: https://www.leychile.cl/Navegar?idNorma=1016076

64. Sgombich, Ximena; Agurto, Irene; Córdoba, Diego; Mena, Susana; Moreno, Aquiles; Ibáñez, Ciro; Debrott, David; Pavlovich; Sebastián. Percepciones sociales respecto del derecho a la salud y expectativas de cambio en el sistema de salud de Chile. Salud Problema, Segunda época, año 12 , número 23 , enero - junio.

65. Ministerio de Salud - MINSAL. Estudio de Opinión a Usuarios del Sistema de Salud y Posicionamiento de la Superintendencia de Salud. Elaborado por Data Voz para la Superintendencia de Salud. Julio 2016. Hallado en enero 2019: http://www.supersalud.gob.cl/ portal/articles-14149_recurso_1.pdf 
66. Larraín, Jorge (2001): Identidad chilena. LOM Ediciones. Santiago.

67. Moulian, Tomás. Chile Actual: Anatomía de un Mito. 1997. LOM-ARCIS. Santiago.

68. The Lancet Global Health Commission. High-quality health systems in the Sustainable Development Goals era: time for a revolution. Lancet Glob Health. Published Online September 5, 2018. http://dx.doi.org/10.1016/S2214-109X(18)30386-3

69. Stolkiner, Alicia. Derechos Humanos y Salud desde el pensamiento Médico Social / Salud Colectiva Latinoamericano. En Jaime Llambías (Ed.), "La enfermedad de los Sistemas de Salud: miradas críticas y alternativas.” 2015. RIL editores.

Artigo apresentado em: janeiro 2019

Artigo aprovado em: fevereiro 2019 Conflito de interesses: os autores declaramnãohaverconflito de interesses Suporte financeiro: não 